\title{
1. Empirical legal research: charting the terrain
}

\section{Willem H. van Boom, Pieter Desmet and Peter Mascini}

\section{INTRODUCTION}

In the academic discipline of the law, scholars have traditionally dealt with legal texts by organizing them, analysing their content from an interpretative, hermeneutical perspective and developing coherent arguments on the law while oscillating between logical deduction, inference and normative claims. Some legal scholars tend to search for logic and order in the continuous and disorderly flow of cases, legislative instruments and policy documents. Others focus their work on building philosophical foundations for the law as it stands or on developing an all-encompassing normative theory of just, fair, efficient or viable law. Most will agree that the academic legal discipline holds legal practice close to its heart and that many law scholars explicitly embrace the practice-oriented character of their teaching and research. Others will be more drawn to understanding the law in its social or philosophical context. There are also scholars who study the law in its social context or as a particular domain of social interaction. These scholars often represent legal subdisciplines with an embedded culture of empirical research - be it socio-legal studies, legal psychology, law and economics, criminology or any other type of research of social legal interaction. Today, therefore, a multitude of academic perspectives on the law impress their mark on law schools: there are those who teach and research positive law as a system which is in constant need of taxonomy, categorization and doctrinal evaluation; those who reflect on its theoretical and philosophical foundations; and those who scrutinize the law from an empirical perspective. ${ }^{1}$

1 On the character of legal scholarship, see, for example, CJJM Stolker, Rethinking the Law School: Education, Research, Outreach and Governance (Cambridge University Press 2014). 
The empirical study of the law has a long history, which is rooted partly in jurisprudence and partly in the social sciences. This research tradition uses as its starting point that positive law is not or ought not to be a purely internal affair, but rather focuses on the behavioural effects of legal instruments or views law in its social context or as a reflection thereof. The empirical study of the law is thought to provide a more realistic view on what the law is, what it does and how it can be improved than one that presents the law as having a unified, cohesive mode of understanding, a distinctive viewpoint or a specific style of interpretation or reasoning. This social scientific shift in looking at the law also seems to have implied a gradual shift in methodology, where traditional legal research is now increasingly being flanked by empirical legal research, consisting of both qualitative and quantitative approaches. It seems that empirical legal research is experiencing a benign tailwind in law schools. While still mostly dominated by black-letter lawyers, law schools seem to be undertaking a slow alteration of disciplinary emphasis by gradually shifting legal research towards empirical legal research, thereby importing methods from sociology, psychology, economics and political science. ${ }^{2}$

What may be driving this gradual shift? Apart from the fact that technological advances over the past decades have made doing empirical research more feasible than before and have prompted law scholars to go where they previously dared not go, the origins of this shift may also have been facilitated by some earlier historical (r)evolutions. One of these is the emergence in the 1960s to 1980s of the disciplines of criminology (including victimology and penology) in criminal law and law and economics in private law. Indeed, through the early incorporation of criminological and economic insights into the areas of criminal law and private law, respectively, these emerging disciplines may have facilitated legal scholars to also adopt empirical methodologies that are common ground in these disciplines. Furthermore, the ascent of empirical legal studies may have been further precipitated by growing criticism that the - originally predominantly theoretical - law and economics scholarship neglects crucial aspects of actual human behaviour by modelling humans as (well-informed) rational actors. ${ }^{3}$ In that sense, empirical legal research has been surfing a wave that originated in economic waters, where the emerging field of behavioural economics - which in turn

2 Ibid.

3 P Mascini Law and Behavioral Sciences: Why We Need Less Purity Rather Than More (Boom Juridische uitgevers 2016). 
stemmed from psychology - has steadily taken a more prominent position alongside traditional theoretical perspectives. 4

The orientation of legal scholars towards society and developments in society may hold a further explanation for the gradual shift. Where society demands answers to empirical questions that fall beyond the reach of traditional legal research, such as how to increase the effectiveness and efficiency of judicial processes, make litigants more satisfied with the legal system and ensure more transparency in judicial reasoning and less legal mumbo jumbo, researchers are matching this demand with empirically grounded research into ways of increasing the effectiveness and efficiency of legal rules and enforcement strategies, litigants' satisfaction and accessibility and the authoritativeness of procedures, rulings and court decisions. Arguably, this social demand has led to an increased supply of more diversified research units consisting of both legal and empirical scholarship.

Regardless of which historical shifts more accurately pinpoint the origin of empirical legal research, its steady rise undeniably illustrates the willingness of lawyers to more accurately understand and interpret natural and social scientific knowledge, to comprehend and explain the behaviour of legal actors and to observe the law in action by grasping its changing role in society and being aware of its effects on individuals and groups. This choice of empirical legal research has now created 'melting pots' within universities that are increasingly experiencing collegial dynamics with both synergistic collaborations and paradigmatic frictions at the frontiers of academic innovation.

At the same time, however, while empirical legal research has taken up an important role in numerous law schools, for many legal scholars it remains a 'black box', with unfamiliar, obscure methods and unclear contributions to the law. It is against this background that this volume is to be understood. We aim to provide lawyers, policy makers and academic researchers with some first-hand insights on the possibilities and limitations of empirical research for legal questions.

To that end, this volume is neither a handbook on empirical legal research nor a teaching manual, but rather a deeper reflection on the approach of different empirical methods in the context of the legal domain. ${ }^{5}$ For the legal scholar who has had limited first-hand experience

4 RB Korobkin and TS Ulen, 'Law and Behavioral Science: Removing the Rationality Assumption from Law and Economics', (2000) 88 California Law Review 1051.

5 As far as handbooks and manuals are concerned, we refer to some of the available literature such as RM Lawless et al, Empirical Methods in Law 
with empirical research, it is often difficult to imagine how the stylized study designs in methodological textbooks translate into actual research activities. In offering findings and reflections by experienced researchers who use a particular methodology in their empirical legal research, this volume's main goal is to show the unique contributions that different methodologies can have for the empirical study of the law. In other words, the starting point of this volume is that the different methodologies are complementary, since each methodology can render visible important, particular elements of juridical reality while being less conclusive about other elements. Therefore, rather than focusing on the technical details, as do other books in this area, this volume sheds light on the current contributions and future prospects and challenges of different empirical methodologies for the study of the various legal domains. We present examples of how empirical research can help answer pertinent questions of legal scholars and policy makers. We do so by letting authors with ample experience in the empirical study of law (broadly defined) reflect on their use of empirical methods, the outcomes generated by their research and the challenges and limitations the choice of methods posed to their research (Chapters 2 to 7 ). The volume ends with legal scholars' reflections on the impact and potential of empirical legal research on academic legal scholarship and legal practice (Chapter 8). The present chapter first reviews some of the main issues involved in empirical legal research, then briefly introduces the chapters in this volume, and ends by discussing a major challenge for bridging gaps between law scholars and empirical legal scholars.

\section{DOCTRINAL LEGAL RESEARCH AND EMPIRICAL LEGAL RESEARCH}

Traditionally, legal research is firmly embedded in teaching and practising the law. Teaching law students is mostly concerned with learning the anatomy of the legal system, the complexities of multilayered (that is, international, crossborder, common law and statute) legal orders and the subtle influence of fundamental rights on the structure of the law. All this

(Wolters Kluwer Law \& Business 2010) and L Epstein and D Martin, An Introduction to Empirical Legal Research (Oxford University Press 2014). Other volumes, although sometimes presented as 'handbooks', are in fact collections of essays arranged on the basis of legal classification. See, for example, P Cane and HM Kritzer (eds), The Oxford Handbook of Empirical Legal Research (Oxford University Press 2010). 
is geared towards application at the bar or on the bench. To achieve this, students are provided skills to interpret and apply statute and case law precedents with both inductive and deductive logic. Moreover, in Western legal academia, the law school experience also seems to ingrain in students' core values concerning the rule of law, protection of weaker parties and the need for balanced democratic institutions and constitutional governance institutions.

This teaching role is firmly connected to doctrinal legal research. This type of research is often seen as a purely intellectual endeavour involving a mixture of logical application of syllogisms, inductive reasoning from cases to principles and teleological interpretation of sources of law with the societal need for balanced outcomes. As the legal system consists of written human interaction, some form of hermeneutics is required to understand, appreciate and apply it, mostly against a specific constitutional and cultural background. Arguably, in hermeneutics much is in the eye of the beholder. This exacerbates the murkiness of doctrinal legal analysis in the sense that it consciously or unconsciously mashes together positive analysis of law as it stands with a normative stance on what the law should be. A piece of doctrinal legal analysis may start out as an effort to chart a certain domain of the legal discipline and end by 'arguing' one point or another, postulating that some solution is 'in line with practical demands', 'strikes a fair balance between ...', 'is just for society', and so on. Such research may turn out to be a conduit for expressing personal opinions or stakeholder opinions, especially if normative underpinnings or assumptions are not made explicit.

Another limitation of doctrinal legal research is its often feeble empirical basis. Lawyers tend to be concerned with solving a problem using their legal toolbox, not with empirically exploring or mapping the problem. Taking as a starting point statements such as 'in practice, we experience this and this problem ...', 'it is said that this and this is a contested issue ...', the lawyer then turns to statute, precedent and relevant fundamental rights to construct the relevant legal issue and create the solutions that seem most suitable for society. If such a suitable solution is difficult to attain, a call for legal reform, parliamentary intervention or judicial activism is voiced.

Undoubtedly, the classical doctrinal approach has added value for legal practice, and therefore also for teaching. Legal practice has an insatiable appetite for handbooks, case digests and other products of high-end doctrinal writing that keep legal practitioners and the judiciary abreast of developments in law. What the empirical study of law can add to doctrinal legal research, however, goes beyond empirical fact-checking, as it enables a deeper understanding of not just the blunt facts, but also 
the underlying mechanisms of legal interaction. For example, empirical research can help to understand what law does and does not represent to people, and may explain what exactly the law does in human and business relations. It may provide insight into deliberate reasoning and unconscious processes in legally relevant decision making. It may provide proof of causal relationships and bring evidence of why certain legal rules do not achieve their intended goals, why they produce unproductive side effects and even how they can be attained more (cost-)effectively with alternative legal arrangements. Hence, empirical research has the enriching potential to inform, underpin and also debunk doctrinal research.

Empirical research can thus complement legal doctrinal research precisely because it is based on different methodological premises. ${ }^{6}$ Firstly, empirical research is committed to 'value freedom'. This is not to say that it is deemed possible to do research that is completely unaffected by the practical values of the researcher - there exists no such thing as 'a view from nowhere'. However, precisely because this is impossible, the researcher is expected to strive to be objective. ${ }^{7}$ So, whereas the 'is' and the 'ought' are often indistinguishable in doctrinal legal research, empirical researchers are more likely to limit themselves to describing or explaining their study topics and to position themselves theoretically. This is not to say that empirical legal researchers are expected to principally refrain from evaluations of the phenomena they have studied or from giving recommendations of what should be done, as some have argued, ${ }^{8}$ but these subjective statements are supposed to be derived from objective findings and accounts of the limitations thereof. Secondly, in comparison with doctrinal research, empirical research uses sources differently. Whereas the power of empirical evidence in empirical legal research is determined by universal criteria such as reliability and validity, in doctrinal legal research authority arguments often play a role in the weight that is attributed to legal sources. ${ }^{9}$ For example, in doctrinal research it is not unusual that the higher the court from which a judgment

6 For discussion about this distinction, see also the chapter by Jan Crijns, Ivo Giesen and Wim Voermans in this volume.

7 M Hammersley, 'Provoking Misunderstanding: A Comment on Black's Defense of Value-Free Sociology’ (2014) 65(3) British Journal of Sociology 492, 494.

8 D Black, 'On the Almost Inconceivable Misunderstandings Concerning the Subject of Value-Free Science' (2013) 64(4) British Journal of Sociology 763.

9 M Hesselink, 'A European Legal Method? On European Private Law and Scientific Method' (2009) 15(1) European Law Journal 20. 
originates, the more seriously it is taken, or that legal interpretations are taken into greater account if the legal writer who provided such interpretations has more standing in the legal community. Finally, it would be wrong to assume that the use of empirical data only pertains to empirical legal research. Although in some philosophical and doctrinal research law is understood in relation to idealized or abstractly imagined social conditions, in other legal research empirical data such as legal cases, texts, legal instruments, legal discourses and legal settings can play an important role in the analysis too. However, whereas in legal research empirical data is often used anecdotally, in empirical research it is analysed systematically with the aim of broadening understanding from the specific to the general. ${ }^{10}$ It is done to assess whether cases are unique or statistically and/or theoretically representative for a larger category or population.

We rely on an inclusive description of empirical research. In the context of the law, empirical research can be described as the systematic and objective collection and classification of observations of social events, circumstances or processes relevant for the operation or the understanding of the law in society. If one were to use this description as a benchmark to classify research in law schools as empirical or not empirical, one could conclude that traditional research methods such as interviewing, courthouse observations and analysing archival records easily fit the description. And in principle they do: they aim to objectively observe facts in a legal context. However, the recent rapprochement between legal scholarship and social science scholarship may in fact be considered by some as fragile. Some legal scholars and social science scholarship may take diverging paths on the issues of theory and methodological rigour. Perhaps one of the reasons why the divide between legal science and social sciences widened after the Second World War, only to be slowly bridged in more recent decades, is a sense of alienation. Some lawyers have perhaps found themselves alienated by the emphasis on ever more sophisticated statistics and stylized experiments in social sciences generally, and the reliance on debatable behavioural models of human behaviour in economics in particular. ${ }^{11}$ We feel

10 R Cotterrell, 'Why Must Legal Ideas Be Interpreted Sociologically?' (1998) 25(2) Journal of Law and Society 171, 183.

11 Cf. DW Vick, 'Interdisciplinarity and the Discipline of Law' (2004) 31 Journal of Law \& Society 189; F Leeuw, 'Empirical Legal Research: The Gap between Facts and Values and Legal Academic Training' (2015) 11 Utrecht Law Review 19-33; R Van Gestel and P Van Lochem, 'Evidence-Based Regulation and the Translation from Empirical Evidence to Legal Norms' (paper under review). 
that this volume should help build bridges, not point fingers at 'less superior methods' or 'lack of practical use'. At the same time, based on concrete examples of empirical research, we want to show that within the realm of empirical legal research, there are fundamental differences between research methods. Just as a linguistic, historic or systematic legal method can result in very different interpretations of an identical legal rule, different methods of empirical legal research can also shed very different light on similar study topics. This means that even though we reject the idea that methods of empirical legal research can be ranked in terms of their scientific value, we also believe different methods have different merits, all of which are important to consider when choosing a method.

\section{EMPIRICAL LEGAL RESEARCH METHODS}

We would like to resist the temptation to further refine our description of empirical legal research, given our objective to strive for an inclusive understanding of it. Nevertheless, some issues of methodology will need attention. There is no sense in debating whether or why a quantitative text analysis of, say, court decisions is in fact 'more empirical' than the classic legal analysis of case law. We feel that any effort to systematically observe and understand the social events, circumstances or processes relevant to the societal operation of the law merits inclusion. Central to this approach is the systematic collection and use of observations, or data, to answer research questions.

Despite the use of data as a common ground, empirical legal research constitutes an umbrella term for a myriad of different methodologies, all rooted in distinct and well-established traditions. Observations can be made directly or indirectly and data can be analysed in quantitative or qualitative ways. Qualitative researchers, for example, may more often turn to interviews to gather observations, whereas quantitative researchers may prefer to go to the lab or the field to collect data via experimentation, surveys or the selection of big data.

Whenever the empirical legal researcher purports to infer relationships from observations, steps in the empirical cycle are taken: a gap in the empirical body of knowledge is identified, an issue explored, theory induced from observations, hypotheses deduced from that theory and then subsequently empirically tested to assess the validity of the theory. Not all steps need to be taken by the same researcher, however, for research to be empirical. Some researchers will focus on induction by using observations to induce new theories. Others may take the deductive 
path and derive specific, testable hypotheses from available theory. The empirical cycle often also takes a different shape for the quantitative researcher and the qualitative one.

As large-scale surveys, expensive lab experiments and field experiments of unique events usually cannot be repeated or adjusted in the meantime, it is crucial that researchers give the best possible answer to their own research question before they start collecting and analysing data. This means that quantitative researchers usually go through the empirical cycle of formulating a research question, confronting theory with empirical data and reflecting on the implications of the research findings for the initial research question only once. Qualitative researchers often follow an iterative process wherein they repeat the empirical cycle every so often until, ideally, they reach a point of saturation. Researchers use observations in the field to adjust, sharpen or expand a preliminary research question, sensitizing concepts and the selection of cases until research problem, theory and findings fit. This means that the formulation of a research question, theory development, the selection of research units and data analysis are usually more entangled in qualitative research than they are in quantitative research - though in both instances new findings lead to new theories and questions, ideally in an everdecreasing circle of expanding scientific knowledge. In practice, however, this ideal of knowledge accumulation is often not achieved. ${ }^{12}$

When engaging in empirical research, scholars have many research strategies at their disposal. In this volume, we highlight the contributions and possibilities of three specific research strategies: one qualitative strategy (case studies) and two quantitative strategies (experiments and (factorial) surveys). Though many more strategies exist, including strategies that involve both qualitative and quantitative steps (that is, mixed methods strategies), these three strategies are the major ones available to the researcher. The experimental study involves a design in which one or more variable characteristics of an object of study are manipulated in one or several instances; the outcomes thus obtained are usually analysed with statistical methods. In a survey study, a single real-life population is selected and queried; the outcome variables obtained from this population are analysed with quantitative tools. In a case study, a single case

12 S Cole, 'The Growth of Scientific Knowledge: Theories of Deviance as a Case Study' in Lewis A Coser (ed.), The Idea of Social Structure: Papers in Honor of Robert K. Merton (Harcourt Brace Jovanovic 1975) 175. 
is or a small number of cases (comparative case study) are selected and explored. Usually, the outcomes are analysed with qualitative methods. ${ }^{13}$

How does one choose between these different research strategies in empirical legal research? Designing research involves choosing the sample (who), the observations (what) and the setting (where), all within the context of the research goal. Research goals have classically been sorted into three broad categories: exploration, description and explanation. ${ }^{14}$ Exploration is typically undertaken when a researcher wants to familiarize him- or herself with the research topic. If the goal is description, then a researcher observes and subsequently describes what was observed, without limiting him- or herself to testing particular theories or hypotheses. Description goals can typically be found in research that uses case studies. At the same time, however, many case studies go beyond description and also examine why an observed pattern exists and what it implies. Those studies aim for what Max Weber identified as 'erklärendes Verstehen' ${ }^{15}$ whereas descriptive studies can answer questions of 'what', 'where', 'when' and 'how', explanatory studies tackle questions of 'why'. The central purpose of explanatory research is therefore to identify the causes and consequences of phenomena and involves making claims about the relationships between variables. Depending on the specific research question that a scholar seeks to answer, some research goals will be more important than others. As a result, some empirical methodologies will also be better suited than others to achieve these goals. To judge the adequacy of a particular methodology, three important criteria have been identified in the literature: control, representativeness and naturalness. ${ }^{16}$

When the research goal is to explain relationships between independent and dependent variables, control is the cornerstone criterion for

$13 \mathrm{~J}$ Dul and T Hak, Case Study Methodology in Business Research (Elsevier, Amsterdam 2008) 4.

14 E Babbie, The Practice of Social Research (10th edn, Thomson Wadsworth 2004) 87-90.

15 Max Weber, Wirtschaft und Gesellschaft (1921; Mohr 1972) 1.

16 The evaluative framework as we present it here is based on PM Golden, The Research Experience (9th edn, FE Peacock Publishers, Itasca, IL 1976) chapter 2. The concepts being used in Golden's book can also be found in most key textbooks on the practice of social scientific research. Influential examples are Babbie (n 14) and LW Neuman, Social Research Methods: Qualitative and Quantitative Approaches (Allyn and Bacon, Boston 2000). We use Golden as our main reference since she links the choice between research strategies to the weighting of different research purposes - an approach we find particularly suitable for the goal of our volume. 
judging the adequacy of the methodology. Control in this context means that the researcher needs to do everything possible to make sure that an observed variation on the dependent variable is due to a variation on the independent variable and not to any other contributing variable, such as an underlying or extraneous unobserved variable. The goal of control is to minimize the amount of variation, both within the subjects and within the environment, that cannot be explained by the independent variable, so that the relationship between the independent and dependent variables can be established unambiguously. Control is therefore related to the concept of internal validity, which also requires precise measurement of behaviour, random assignment or the inclusion of control variables that enable causal conclusions. Representativeness is a criterion that describes the extent to which a group of instances is representative for the larger group of which it is a subset. Instances in this respect can pertain not just to the sample, where representativeness would mean the extent to which the subjects in a researcher's sample are representative for the population he or she wants to study, but also to the extent to which the observed variables (for example, stealing in a laboratory context) are representative for the category of variables the researcher wants to make conclusions about (for example, crime in general). Representativeness is therefore related to the concepts of generalizability and external validity. Therefore, the representativeness of a smaller group is the degree of similarity between the distribution of the values of the variables in the two groups, as well as the degree of similarity between the causal relations observed in this group and in the larger group. ${ }^{17}$ Moreover, to quote Golden,

When a primary concern is understanding the system character of the context of a particular phenomenon or event, the naturalness of the behaviour and the setting becomes the most important criterion for judging the adequacy of the research strategy. The focus is on the complex, ongoing patterns of interaction brought about by 'real' social entities performing their normal activities in a natural setting. ${ }^{18}$

The balance between these three research goals differs between the three methodologies that are addressed in this volume.

17 Dul and Hak (n 13) 45.

18 Golden (n 16) 15. 


\section{Experiments}

In experiments, researchers manipulate one variable to see its effect on another. When one is testing a hypothesis about a particular relationship between variables, control is of paramount importance. Because in experiments researchers have control over the independent variable, the experiment is the best candidate when one wants to maximize control and make causal claims about relationships. Two types of studies are available to the experimental researcher: laboratory experiments and field experiments.

\section{Laboratory experiments}

The laboratory experiment typically allows the researcher to have the highest amount of control possible. By manipulating the independent variables central to the investigation, and by holding constant other extraneous environmental and personal variables through random assignment, laboratory experiments can provide the most complete level of control. In a prototypical experiment, subjects are randomly assigned to a control group (without manipulation of the independent variable) or a treatment group (with manipulation of the dependent variable). This manipulation can happen between subjects (each subject is assigned to only one group) or within subjects (subjects participate both in a control and in a treatment group). By comparing observations between groups, the experimental researcher is able to isolate the effect of the independent variable on the dependent variable, which is a necessary condition that must be met in order to approximate the establishment of causal relations. In order to be able to uncover a causal relationship between two variables, the following conditions must be met: there is a significant correlation between the variables; the causal (independent) variable precedes the variable caused (dependent variable) in time and there are no other variables that determine the correlation between the variables; there is no spurious relationship. ${ }^{19}$ To achieve this, the experimental researcher usually creates a very specific context in which everything except the independent variable is kept constant and the amount of variables studied is typically limited. This specificity and control in laboratory experiments, however, also provides the basis for the most prevalent criticism of this research method: although laboratory experiments are high on internal validity, they can be weak on external validity,

19 J Segers and J Hagenaars, 'Onderzoeksstrategie en ontwerp-principes' ('Research Strategy and Design Principles') in J Segers (ed.), Methoden voor de maatschappijwetenschappen (Van Gorcum, Assen 1999) 369, 378-9. 
which means that findings cannot be automatically generalized to other individuals, other settings or other behaviour in real life. There are, however, ways in which the experimental researcher can increase external validity and naturalness by bringing the field into the lab to a greater degree. Therefore, depending on the population, the context or the behaviour about which a researcher wants to derive conclusions, the experimental researcher has to be careful in choosing his sample of subjects, the experimental context and the way in which the independent and dependent variables are operationalized in order to increase the external validity and naturalness of the results. The strength of laboratory experiments is that they are strong on control and the inference of causal relationships, but caution is needed in judging their naturalness and representativeness. Laboratory experiments are most likely to be used in explanatory research.

\section{Field experiments}

Field experiments combine some of the advantages of both field studies and experiments, as they experimentally examine an intervention in the real world rather than in the laboratory. By studying phenomena in the real world, field experiments' external validity and naturalness are typically considered to be higher than in laboratory experiments, where the situation is more controlled, yet more artificial. Yet taking an experiment to the field may sometimes also pose problems and it is difficult to have the same amount of experimental control as in the laboratory. Random assignment can sometimes be difficult in the field, leaving the possibility that extraneous environmental variables still influence the outcome of field experiments. Field experiments are typically used for explanatory research and have the advantage of higher naturalness and generalizability. They can, however, (sometimes) suffer from a lack of control.

\section{Survey Research}

Survey research is typically conducted when the researcher wants to obtain information from a large amount of people in order to formulate conclusions that are generalizable to a larger population. Accomplishing this generalizability requires using samples that are representative for these larger populations. Surveys are good vehicles to quantitatively describe attitudes, orientations and behavioural intentions in a large population. The phenomenon being studied is often but not necessarily independent of particular settings. Surveys also allow for inference of relations between variables of interest, but the fact that there is no 
manipulation of the independent (causal) factor makes it more difficult to derive conclusions about causality. However, several choices in the design of surveys can reduce this lack of control and increase confidence in causal claims; some of these are the inclusion of statistical control variables, opting for longitudinal instead of cross-sectional designs or choosing a factorial survey design. For example, in time series the survey is repeated periodically in the same population but with different respondents, while a panel study is repeated periodically with the same respondents. The intrinsic validity of these two dynamic types of survey research can be threatened by external events impacting on correlations and changes of measurements. ${ }^{20}$ The major advantage of panel research relative to time series is that changes at individual level can be determined and further analysed using the other variables concerning the respondent. Yet, precisely because the composition of the research sample has to remain the same in all research rounds, loss of respondents is often a dramatic factor, as it occurs at each research round and thus becomes cumulative.

While some would argue that the naturally occurring interaction of factors is not altered in surveys, others would counter that the introduction of the survey instrument is reactive in itself and creates a totally unnatural situation. ${ }^{21}$ Another criticism of surveys is that they consist of self-reported attitudes and behaviour, which makes these observations vulnerable to social desirability bias and can raise questions regarding the extent to which these self-reported observations correspond to actual attitudes and behaviour.

In summary, surveys use samples which are independent of settings; they aim to provide conclusions regarding a larger, representative part of a population and are therefore strong on representativeness. Although they do not have the same level of control as laboratory experiments, specific designs and statistical controls can increase this control in order to make causal claims. The independence of research topics from particular settings and the self-reported nature of surveys challenge the naturalness of this method. Surveys are used both for descriptive and explanatory research.

20 Ibid 391-2.

21 Golden (n 16) 18. 


\section{Case Study Research}

Unlike experimental setups or survey research, case studies are often conducted using a variety of methods and a variety of source materials. Therefore, the case study is less a single research method than a research approach. ${ }^{22}$ Case studies come closest to approximating real life. There is maximum concern with understanding the patterns of interaction in a particular context. As such, case studies do lend themselves to openness, flexibility and discovery. Yet, precisely because case studies aim to study the interaction of many variables in a particular setting as fully as possible, they are less suitable for focusing on or isolating specific elements of the research situation. Because control is difficult to achieve in case studies, and because the number of observations is relatively small compared to experiments and surveys, causality and generalizability are particularly difficult to achieve in case studies. However, there are ways to partly overcome these limitations.

In relation to causality, case studies can be particularly strong when attempting to explain a single situation in its unique, separate, peculiar or distinct character, or idiosyncratic detail, or what is identified as idiographic explanation'. ${ }^{23}$ For the latter purpose, case studies with longitudinal characteristics are particularly suitable. Such case studies enable process tracing - documenting in detail how the outcome of interest is generated - and whether this process matches expected theoretical patterns. Case studies can also fulfil different roles in relation to the nomothetic, generalized explanations that experiments and surveys typically offer. First, case studies can form a basis for the development of more general, nomothetic theories by generating hypotheses. Second, case studies can have the purpose of discovering flaws in, and then modifying, existing social theories. Third, the goal of controlled comparison designs can be used to establish the necessary or sufficient conditions for an event to occur. Important principles of controlled comparison designs are to compare cases that have different outcomes and are either highly similar to one another but differ in one or only a few significant respects, or to compare cases that have similar outcomes and are highly dissimilar to one another but are similar in one or only a few significant respects. Although extraneous variables may still exist, by building

\footnotetext{
22 See the chapter by van Oorschot and Mascini in this volume.

23 Babbie (n 14).
} 
comparisons in such a way, one may obtain greater confidence that any relationship between a given factor and an outcome is indeed causal. ${ }^{24}$

What is important in terms of generalizability of case studies is that researchers usually do not leave the selection of cases to chance, but select cases purposively based on theoretical reasoning. This means that whereas survey research strives for statistical generalization - in which case the goal is to test the representativeness of findings pertaining to a randomly selected sample to the population from which the sample is drawn - the case study is usually focused instead on achieving theoretical generalization - in which case purposively selected cases represent a larger class of cases (a population). ${ }^{25}$ By following a replication rather than a sampling logic, the theoretical generalizability of propositions can be tested in multiple-case studies. ${ }^{26}$ In multiple-case studies the findings of different cases may be compared based on predictions formulated at the outset of the investigation, either with (serial set of single case studies) or without (parallel set of single case studies) taking into account the outcome of previous tests. ${ }^{27}$

In summary: case studies use real groups in natural settings; they focus on a particular context and are strong on naturalness but weaker on control and representativeness. While case studies are used most often in explorative and descriptive research, explanatory purposes should not be ruled out.

Having described the broad characteristics of three different methods and the consequences that their choice entails, let us now stress that the choice of a particular methodology sometimes not only depends on the problems, purposes and goals of the research, but is also guided by familiarity, personal preferences and backgrounds of the researchers and practical possibilities or obstacles.

The choice of a particular method can, first of all, be influenced by the disciplinary background of the researcher. For instance, an anthropologist may have a different outlook on ontology and epistemology compared to a psychologist or an economist. This may in turn cause legal anthropologists to develop research aims that are different from those of legal psychology scholars or law and economics scholars. Whereas the former

\footnotetext{
24 See the chapter by Etienne in this volume.

25 Jason Seawright and John Gerring. 'Case Selection Techniques in Case Study Research: A Menu of Qualitative and Quantitative Options’ (2008) 61(2) Political Research Quarterly 294.

26 RK Yin, Case Study Research: Designs and Methods (2nd edn, Sage Publishers 2005) 51. See also ibid.

27 Dul and Hak (n 13) 45.
} 
may consider the deeper understanding of the societal embeddedness of a certain legal process in all its richness and complexity as the main research aim, thereby avoiding the testing of specific hypotheses, the latter may be drawn more to the process of identification and experimental manipulation to establish the causative power between a limited set of variables in that same legal process. When asked, chances are that all types of researchers will state that their ulterior aim is to understand how law and society interact, how individuals respond to law and how law can be understood in its social context, but their research designs and conclusions will look sharply different.

The choice of a particular method can also be driven by more pragmatic concerns, such as the availability and feasibility of observations. Surveys and quantitative studies typically require a greater number of observations in order to make firm conclusions, but for some domains collecting big samples is often very difficult, if not impossible. For decent qualitative studies, sample size is less important; however, gaining access to the research field may be an obstacle. Likewise, experimental manipulation is not always feasible - not just in field experiments, where random assignment to different legislation is impossible, for instance, but also in the lab, where studying the deterrent effects of capital punishment would probably not pass through an ethics committee. In that case, interviews or surveys with criminals on death row, flanked by a quantitative analysis of capital crime rates across different jurisdictions, may be more feasible.

Hence, choosing between research methodologies is a balancing act in which substantive, personal and pragmatic considerations all play a role.

\section{OVERVIEW OF THE CHAPTERS}

In this volume, we want to present readers with the greatest possible number of real-life examples of how empirical research can help answer pertinent questions of legal scholars and policy makers. In doing so, we hope to introduce lawyers and others who are less familiar with empirical research to the concept of empiricism itself, the way in which empirical research can help answer some of the questions that legal scholars and policy makers face and the challenges and prospects for empirical legal research in the future. Chapters 2 to 7 are devoted to the different research strategies' application to three legal domains. 
Chapter 2, by Hilke Grootelaar and Kees van den Bos, serves two purposes. Firstly, the authors show readers important aspects that empirical researchers have to take into consideration when designing experiments and surveys. By taking the legitimacy of administrative decision making as the central object of investigation, the authors illustrate the methodological rigour that is required in the empirical process. They also highlight both the benefits and limitations of conducting experiments by contrasting the method with correlational survey research.

Whereas Chapter 2 provides a firm introduction to the questions that empirical researchers have to ask in the process of designing experiments and surveys, in Chapter 3 Christoph Engel dives into the literature to illustrate the accumulated contributions that experiments have made in the context of criminal law. After pinpointing the major strengths of experimentation and its rigorous ways of identifying cause and effect, Engel introduces readers to the main experimental methods available lab and field experiments - as well as to experiments with or without context. What follows is an extensive literature review in which Engel showcases the impressive amount of evidence that experiments have generated in two major criminal law domains: crime (including theft, fraud, tax evasion and corruption) and intervention (deterrence and the effects of sanctions). Engel's detailed review leaves readers no other conclusion than that the existing body of experimental evidence is a vast, valuable, yet rarely used resource.

In Chapter 4, Christopher P. Reinders Folmer picks a different domain to illustrate the relevance of experimental methods for legal research. The author starts by arguing that the inherent variability of cases in legal practice places important constraints on the conclusions that can be drawn from observations in actual litigation. Experimental approaches provide a powerful tool for legal scholars and policy makers to counter such limitations. Experimental approaches examine legal questions by means of laboratory or field experiments, which simulate litigation contexts, or experimentally test initiatives in actual litigation practice. In these approaches, key features (for example, the presence or absence of apologies) are varied systematically, while variability on other factors (for example, between types of tort, level of harm, and so on) is minimized. In this way, the researcher can isolate the unique effects of particular actions, initiatives or features that cannot be separated in legal practice - or which have not yet been implemented there (for example, proposed reforms). As such, Reinders Folmer shows that experimental approaches provide unique insight that can enrich and advance legal scholarship and practice, by providing causal evidence that speaks to the validity of the assumptions and presumptions on which legal theorizing 
and policy are based. This process is illustrated by reviewing experimental approaches in the domain of personal injury litigation and applying their conclusions to the current discussion on the sufficiency of its extant litigation designs, and the direction of their future reform.

In Chapter 5, Melissa Rorie, Sally S. Simpson and Breanna Boppre describe how factorial surveys are (and can be) used to study the impact of environmental law and enforcement on corporate compliance. The authors begin by outlining the benefits and limitations of the factorial survey method. They then review the literature on how factorial surveys have been used to examine the administration of environmental regulations. In this review, Rorie, Simpson and Boppre find that factorial surveys have been underutilized in the study of environmental enforcement, despite the unique opportunities for knowledge building provided by this method. As such, they discuss the usefulness of this method for the study of administrative law and outline potential avenues for future research.

Chapters 6 and 7 focus on case study research. In Chapter 6, Julien Etienne argues that the empirical literature on administrative law, particularly on regulation, in recent years has been enriched by a limited number of case studies. Some of these contributions are 'pure' single case studies, driven towards generating new hypotheses and theories. Other contributions rely on the basic rules of the case study, but incorporate them within comparative designs, so that they may set up confrontations between the evidence emerging from different cases. In this chapter, besides making reference to several relevant publications, Etienne discusses the main elements, merits and limitations of these methods. He draws from his own experience, where he reflects on earlier work on a case study and a comparative study. The case study concerned administrative law applicable to hazardous industrial sites in France. The comparative study explored the same broad topic but set the case of France against that of the UK. Both studies provide a powerful counterpoint to a number of assumptions underpinning the administrative law dispositions involved. They also provide a level of detail on the dynamics of the law in practice that other methodologies would easily miss. Furthermore, the case study approach enabled drawing numerous additional hypotheses that could be tested in future research.

In Chapter 7, Irene van Oorschot and Peter Mascini seek to demonstrate the use of the case study for criminal law. They argue that since case studies are often conducted using a variety of methods and a variety of source materials and can assume very different forms - that is, single or multiple cases and single or multiple units of analysis - the case study confronts the researcher with important decisions to be made throughout 
the entire process, taking into account one's own theoretical expectations, the various uses of different methods and the limitations of one's access to the phenomenon under study. Working through the experience of doing a case study of a Dutch criminal court, the authors demonstrate the intricacies of making such choices and their consequences to the 'case' they were eventually able to make. In order to 'make their case', the authors used as their guiding research question how the judges of a magistrates' court in the Netherlands arrive at their decisions as a matter of everyday work practice. By opening the black box of judicial decision making, the researchers aimed to use, in a complementary way, survey research and experimental research design, which tends to problematically isolate the impact of legal and nonlegal factors on sentence outcomes and tends to ignore the processes and mechanisms that take place in between. They also sought to call into question juridical understandings of adjudication and sentencing that understand these activities as purely cognitive or intuitive leaps in the rule-governed dark.

In Chapter 8, the criminal law scholar Jan Crijns, administrative law scholar Wim Voermans and private law scholar Ivo Giesen jointly shed light on the interface between legal scholarship and empirical legal research. The authors aim at answering the questions of what the importance is or could be of empirical methods for legal research as it is currently being performed within the legal domain, and which constraints and limitations are then to be reckoned with. Following a short general introduction, they inventory some of the peculiarities of 'regular' or 'traditional' doctrinal legal research. Next, they explore possible explanations for the seemingly slow reception of empirical scholarship within legal research. This allows them to focus on the added value that empirical research methods might have on offer for private law, criminal law and constitutional and administrative law. In the process, they identify the main pros and cons, from a legal scholarship perspective, of the empirical research methods dealt with elsewhere in this volume.

\section{CHALLENGES AHEAD}

After setting out the ambitions of this volume, introducing the field of empirical legal research and announcing the subsequent contributions, we would like to conclude this brief introduction with points for reflection.

One of the challenges for bridging the gap between law scholars and empirical legal research scholars concerns the perception of the fundamental raison d'etre of scholarship. Although more true for some countries than others, our impression is that legal academic scholarship is 
typically entwined with legal practice and policymaking. The consequence may be that lawyers have a particular view on what constitutes valuable knowledge and on what is the pinnacle of good research.

In terms of what is and what is not 'valuable knowledge', it bears keeping in mind that lawyers are trained to render reasoned decisions in real life. Take for instance the concept of evidence of causation. Whereas in statistics a probabilistic understanding of causation is dominant, lawyers are educated as decision makers who transpose probabilities into determinist certainties for the sake of persuasion, adjudication and conflict termination. At the end of the day, lawyers need to render decisions to identify responsible culprits, to allocate risks and to restore or affirm societal order, all in accordance with the applicable legal standards and principles. To be fair, these standards and principles are not the subtle scientific instruments used to 'increase the body of knowledge' but rather the rough and ready tools to end dispute and adjudicate with finality; as a result, they tend to be deterministic, not frequentist or probabilistic. This does not mean that lawyers are unaware of the fact that these decisions are made under conditions of uncertainty. It does mean, however, that lawyers are not educated to see probabilities, distributions and percentages as more valuable approximations of certainty than a persuasive narrative. This professional training trickles down to every aspect of research.

As far as 'good research' is concerned, the prototypical lawyer will strive to make a mark on court briefs, rulings, legislative proposals, political discussions and legal practice. Perhaps that type of influence is just as important (and for some even more important) than gaining traction among peers by reference to the number of citations of their work. If this impression is correct, we can conclude that the prototypical legal scholar is interested in influencing institutions and thus contributing to a more just world. By contrast, for some social scientists increasing the body of (theoretical) knowledge is the main concern, preferably through publication in scholarly journals valued by peers.

The result may be that if a better understanding or an increase in the body of knowledge does not translate into practical proposals for improving the law and 'making the world a bit more just', this legal scholar and social scientist will have little in common. 'Never the twain shall meet' unless they explore and foster their commonalities. It is exactly this process that we aim to support in this volume. 


\section{BIBLIOGRAPHY}

Babbie E, The Practice of Social Research (10th edn, Thomson Wadsworth 2004).

Black D, 'On the Almost Inconceivable Misunderstandings Concerning the Subject of Value-Free Science' (2013) 64(4) British Journal of Sociology 763.

Cane P, Kritzer HM (eds), The Oxford Handbook of Empirical Legal Research (OUP 2010).

Cole S, 'The Growth of Scientific Knowledge. Theories of Deviance as a Case Study' in Coser LA (ed.), The Idea of Social Structure: Papers in Honor of Robert K. Merton (Harcourt Brace Jovanovic 1975) 175-220.

Cotterrell R, 'Why Must Legal Ideas Be Interpreted Sociologically?' (1998) 25(2) Journal of Law and Society 171, 183.

Dul J, Hak T, Case Study Methodology in Business Research (Elsevier 2008).

Epstein L, Martin D, An Introduction to Empirical Legal Research (OUP 2014).

Golden PM, The Research Experience (9th edn, FE Peacock Publishers 1976).

Hammersley M, 'Provoking Misunderstanding. A Comment on Black's Defence of Value-Free Sociology' (2014) 65(3) British Journal of Sociology 492.

Hesselink, M, 'A European Legal Method? On European Private Law and Scientific Method' (2009) 15(1) European Law Journal 20.

Lawless RM, Robbennolt JK, Ulen T, Empirical Methods in Law (Wolters Kluwer Law \& Business 2010).

Leeuw F, 'Empirical Legal Research: The Gap between Facts and Values and Legal Academic Training' (2015) 11 Utrecht Law Review 19.

Korobkin RB, Ulen TS, 'Law and Behavioral Science: Removing the Rationality Assumption from Law and Economics' (2000) 88 California Law Review 1051.

Mascini P, Law and Behavioral Sciences: Why We Need Less Purity Rather Than More (Boom Juridische uitgevers 2016).

Neuman LW, Social Research Methods: Qualitative and Quantitative Approaches (Allyn and Bacon 2000).

Seawright J, Gerring J, 'Case Selection Techniques in Case Study Research: A Menu of Qualitative and Quantitative Options' (2008) 61(2) Political Research Quarterly 294.

Segers J, Hagenaars J, 'Onderzoeksstrategie en ontwerp-principes' ('Research Strategy and Design Principles') in Segers J (ed.), Methoden voor de maatschappijwetenschappen (Van Gorcum 1999) 369-400.

Stolker CJJM, Rethinking the Law School: Education, Research, Outreach and Governance (CUP 2014).

Van Gestel R, Van Lochem P, 'Evidence-Based Regulation and the Translation from Empirical Evidence to Legal Norms', paper under review.

Vick DW, 'Interdisciplinarity and the Discipline of Law' (2004) 31 Journal of Law \& Society 189.

Weber M, Wirtschaft und Gesellschaft (1921; Mohr 1972).

Yin RK, Case Study Research: Designs and Methods (2nd edn, Sage Publishers 2005). 